\title{
A New Technique Using Ultra-slim Endoscopy for High- Grade Crohn's Stricture
}

\author{
Ga Hee Kim, Kyung-Jo Kim, Gi Ae Kim, Jee Eun Yang, Hee Jung Park, Byong Duk Ye ${ }^{1}$, Seung-Jae Myung ${ }^{1}$, \\ Suk-Kyun Yang ${ }^{1}$ \\ Departments of Internal Medicine and ${ }^{1}$ Gastroenterology, Asan Medical Center, University of Ulsan College of Medicine, Seoul, Korea
}

Crohn's disease (CD) is a chronic inflammatory bowel disease of unknown etiology. Most patients with CD will eventually develop a stricturing or penetrating complication. Colonoscopic findings may predict the clinical course in patients with $\mathrm{CD}$. Moreover, since CD patients are at increased risk for developing dysplasia and colorectal cancer, surveillance colonoscopy is necessary for the detection of malignancies. We describe here a CD patient with a high-grade anorectal stricture who successfully underwent a total colon examination with an ultra-slim upper endoscope after an insertion failure with a standard colonoscope and gastroscope.

Keywords: Crohn disease; Stricture; Ultra-slim upper endoscope; Gastroscopes

\section{INTRODUCTION}

Crohn's disease (CD) is a chronic inflammatory bowel disease (IBD) of uncertain etiopathogenesis. Most patients with CD will eventually develop a stricturing or penetrating complication [1]. Colonoscopy may predict the clinical course in patients with CD because deep and extensive ulcerations are associated with increased risks of complications and surgery $[2,3]$. Moreover, because $\mathrm{CD}$ patients are at increased risk for development of dysplasia and colorectal cancer (CRC), periodic colonoscopy is essential for the surveillance of malignancies [2].

We describe here a CD patient with a high-grade anorectal stricture who successfully underwent a total colon examination with an ultra-slim upper endoscope (GIF-XP260N; $5.0 \mathrm{~mm} \varnothing$ with an instrumental channel of $2.0 \mathrm{~mm} \emptyset$; Olympus Co., Tokyo, Japan)

Received: April 9, 2012 - Accepted: May 30, 2012

Correspondence to: Kyung-Jo Kim, M.D.

Department of Gastroenterology, Asan Medical Center, University of Ulsan College of Medicine, 88 Olympic-ro 43-gil, Songpa-gu, Seoul 138-736, Korea

Tel: +82-2-3010-3196, Fax: +82-2-476-0824

E-mail: capsulendos@gmail.com

(C) 2012 The Korean Society of Coloproctology

This is an open-access article distributed under the terms of the Creative Commons Attribution NonCommercial License (http://creativecommons.org/licenses/by-nc/3.0) which permits unrestricted noncommercial use, distribution, and reproduction in any medium, provided the original work is properly cited. after failure with a standard colonoscope (CF-H260AI, Olympus Co.) and gastroscope (GIF-P230, Olympus Co.).

\section{CASE REPORT}

A 37-year-old man, diagnosed with CD in 1999, presented with diarrhea and a perianal fistula. He had been treated with mesalazine, $3 \mathrm{~g} /$ day, but had not undergone a colonoscopy since the diagnosis because of a high-grade stricture in the anorectum. In 2002, he was referred to our gastrointestinal department for a second opinion on his CD. Diarrhea and intermittent abdominal pain developed three months before admission. An abdominal computed tomography (CT) scan demonstrated diffuse bowel-wall thickening and enhancement throughout the ileum and colon with multifocal strictures (Fig. 1). Laboratory data were unremarkable. After informed consent had been obtained, a colonoscopy was performed to assess disease activity and as surveillance for cancer. At three centimeters from the anal verge, however, passage of both a standard colonoscope and gastroscope (GIF-P230, $8.5 \mathrm{~mm} \varnothing$; Olympus Co.) was blocked due to severe anal stricture (Fig. 2A). We, therefore, performed a colonoscopy with an ultra-slim upper endoscope (GIF-XP260N, Olympus Co.), which passed through the rectal stricture without any resistance (Fig. 2B). Although other focal strictures were found in his transverse (Fig. 3C) and sigmoid (Fig. 3D) colon, we succeeded in reaching the cecum (Fig. 3A) in 3 minutes, but we failed to reach the terminal ileum 
Journal of The Korean Society of A New Technique Using Ultra-slim Endoscopy for High-Grade Crohn's Stricture

\section{Coloproctology Ga Hee Kim, et al.}

due to a narrowed ileocecal valve (Fig. 3B). Careful examination of the colon revealed a huge ulcer in the transverse colon. Biopsies were taken from the mucosa of the anal stricture to rule out colon cancer. These biopsies showed no evidence of malignancy.

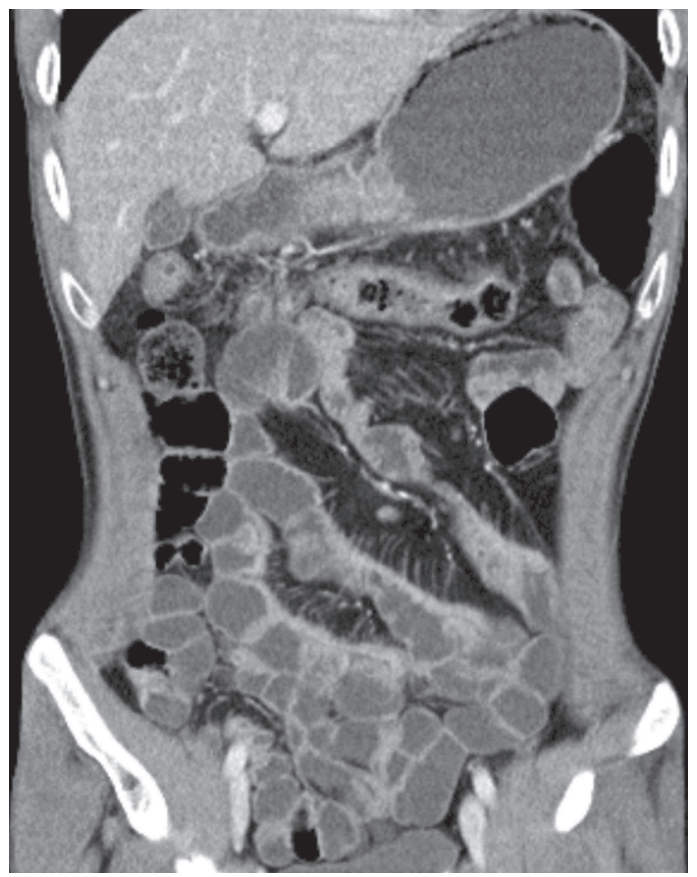

Fig. 1. Computed tomography scan showing a multiple colonic stricture, mesenteric root enhancement, and pseudosacculation in the antimesenteric border of a small bowel loop.

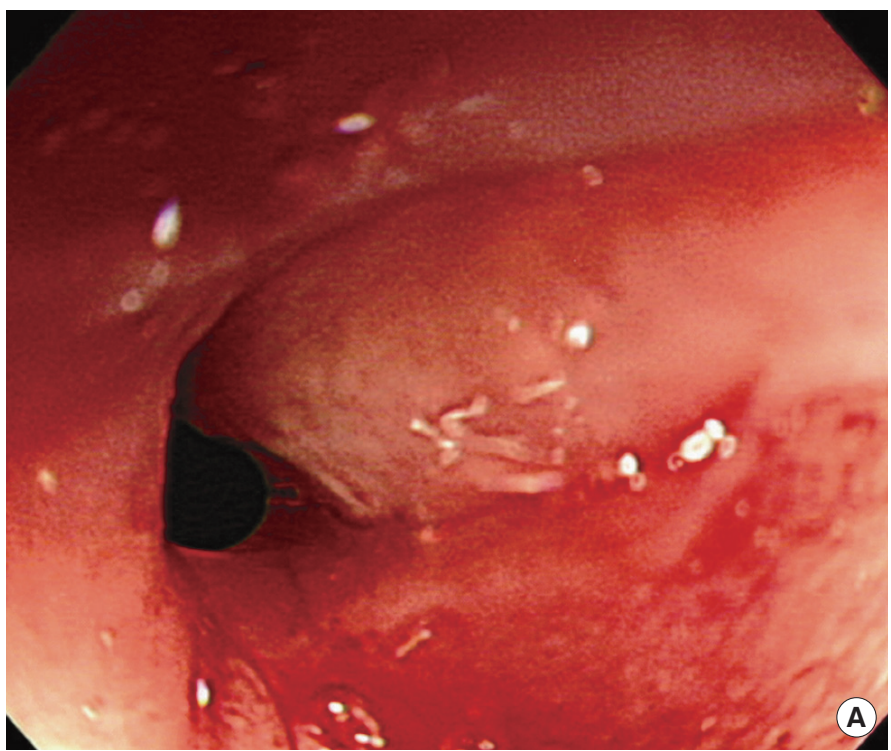

\section{DISCUSSION}

The primary advantage of a small-caliber endoscope over a standard colonoscope is its smaller diameter and greater flexibility, making it more suitable for patients with narrowed colons. Although full colonic examination by ileal intubation using a smallcaliber upper endoscope (GIF XP160, $5.9 \mathrm{~mm} \varnothing$; Olympus, Tokyo, Japan) (Fig. 4) has been shown to be feasible in non-IBD patients [4], to our knowledge, there have been no reports describing the use of an ultra-slim upper endoscope for total colonoscopy in $\mathrm{CD}$ patients with strictures. Our patient had never undergone a colonoscopy due to high-grade anal and colonic strictures. The ultra-slim upper endoscope was useful for examining the total colon and for taking biopsies.

A mucosal evaluation using an ultra-slim endoscope has two advantages. After introduction of a biologic agent, mucosal healing is likely to predict a more sustained clinical remission and a better long-term outcome. In addition, because CRC is a problem in patients with long-lasting $\mathrm{CD}$, the use of an ultra-slim endoscope may make surveillance and biopsies possible. In addition, although $\mathrm{CD}$ patients with strictures and prestenotic dilatation, as well as all medically-refractory patients with $\mathrm{CD}$, should be considered candidates for surgery, asymptomatic patients and those with mild symptoms require frequent endoscopic examination.

Notable characteristics of the gastroscope are a smaller suction channel, which makes it more difficult to clear liquid stool/debris, and its operative channel, whose exit is opposite that of the colonoscope. Various techniques may be used to overcome these differences. When using a gastroscope for colonoscopy, more torque is necessary because of its limited angulation range (up/down

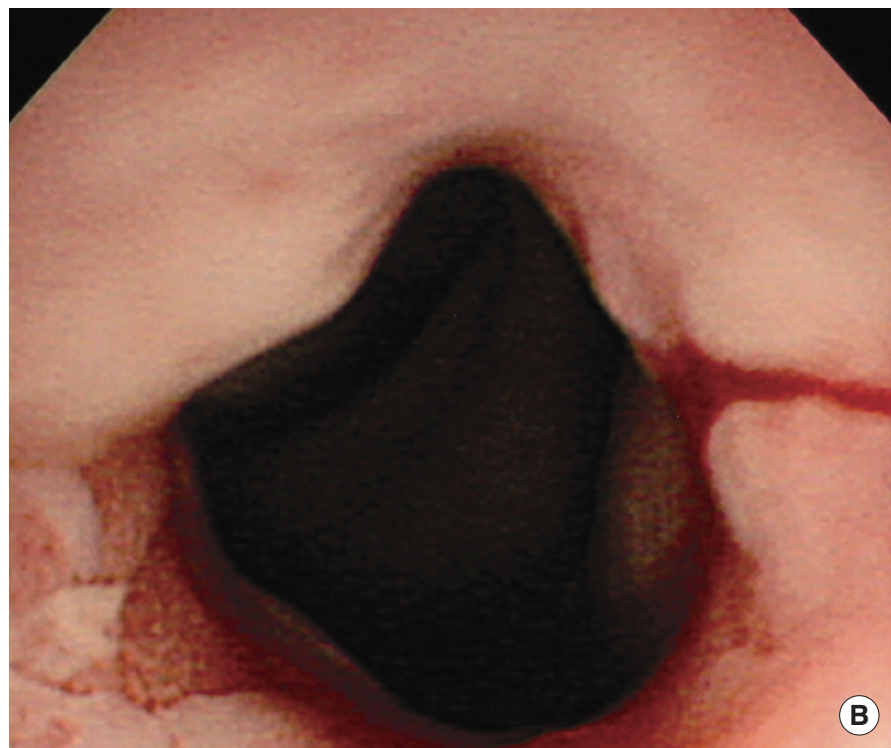

Fig. 2. Endoscopic view of the anorectal stricture: (A) initial colonoscopy, showing a luminal stricture with ulceration and inflammatory exudates, and (B) second endoscopic view using ultra-slim upper endoscopy. 

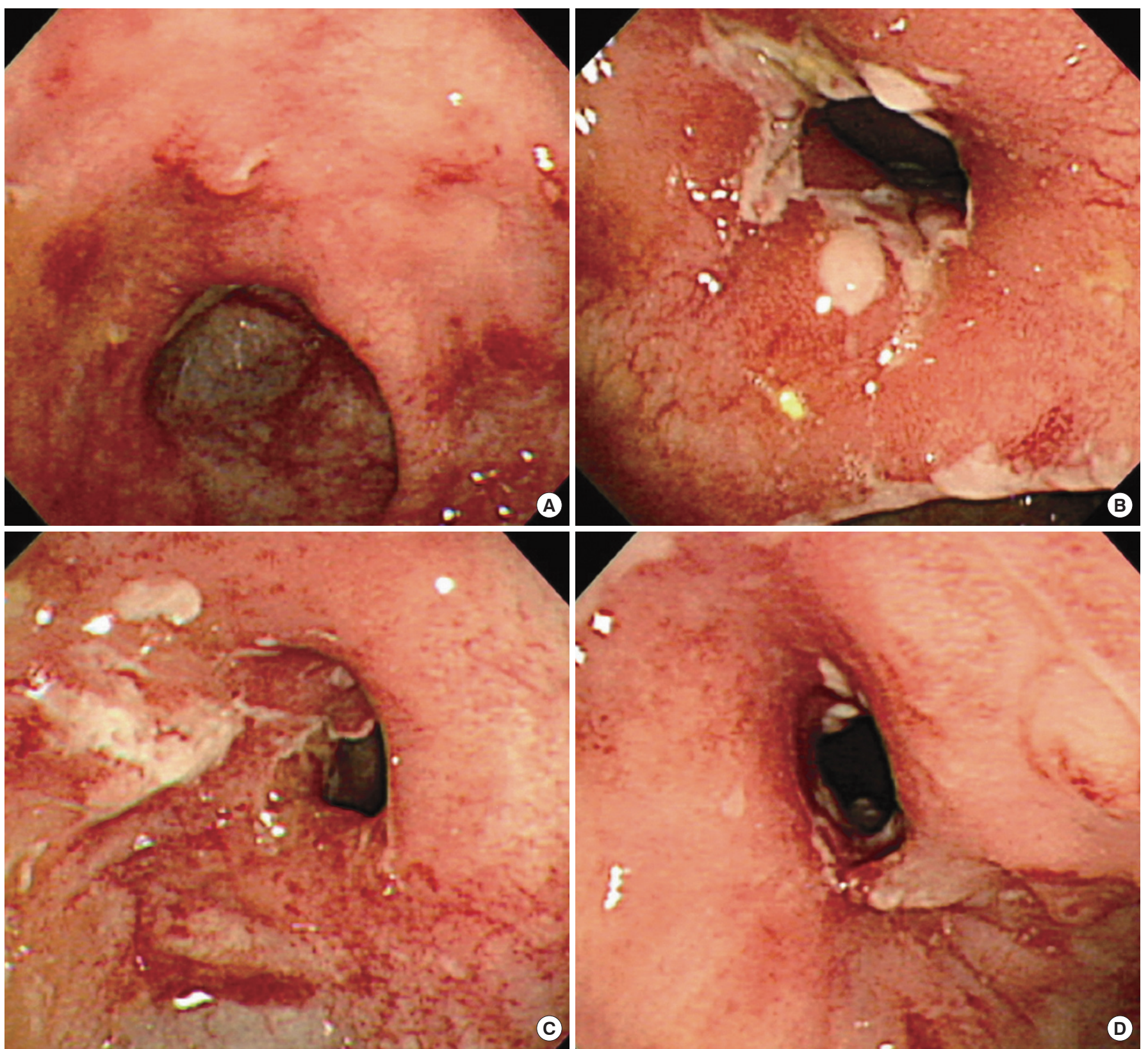

Fig. 3. Ultra-slim upper endoscopic views: (A) ulceration and erosion in cecum, (B) Crohn's stricture on the mucosa of the ileocecal valve, (C) Crohn's stricture and a huge ulceration in the transverse colon $55 \mathrm{~cm}$ from the anal verge, and (D) Crohn's stricture in the sigmoid colon $25 \mathrm{~cm}$ from the anal verge.

$210^{\circ} / 90^{\circ}$ and right $/$ left $100^{\circ}$ vs. in a colonoscope, up/down $180^{\circ}$ and right/left $160^{\circ}$ ). Also, a gastroscope is more rigid than a colonoscope, and an endoscopist knows that he or she has previously failed the index examination [5].

Colonoscopy in this patient was performed by an expert (KKJ) without any complications. The primary concerns associated with colonoscopy in patients with high-grade strictures are its operator-dependent nature and its higher risk of perforation [6]. As long as appropriate care is taken, colonoscopy with an ultra-slim upper endoscope might be feasible and useful in selected patients with CD strictures.

Moreover, colonoscopy using a gastroscope may be useful even though there have been no reports describing the use of an ultraslim upper endoscope for total colonoscopy in patients with stricturing CRC. However, compared to IBD patients, examining the entire colon may be difficult even though passing through the en- 


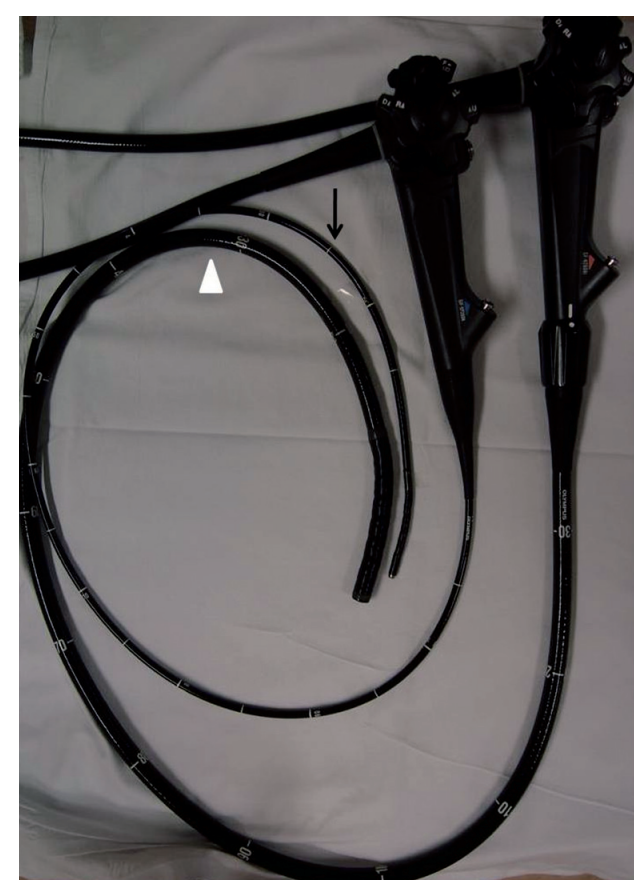

Fig. 4. Left (arrow), ultra-slim upper endoscope (GIF-XP260N, 5.0 $\mathrm{mm} \varnothing$ with instrumental channel $=2.0 \mathrm{~mm} \varnothing$, working length $=110$ cm; Olympus Co., Tokyo, Japan). Right (arrow head), standard colonoscope (CF-H260AI, $12.9 \mathrm{~mm} \varnothing$ with instrumental channel $=3.7$ $\mathrm{mm} \varnothing$, working length $=133 \mathrm{~cm}$; Olympus Co.)

tire colon may be possible. A plausible explanation for the greater difficulty is that the healed colon in patients with IBD tends to be shortened compared to its original length. However, a colon with stricturing CRC is not shortened. Instead, a study reported that CT colonography may have a role in the evaluation of the more proximal colon in patients with stricturing colon cancer [7]. In summary, when CD patients with anorectal stricture are encountered, gastroscopy could be a reasonable diagnostic option for a colon examination

\section{CONFLICT OF INTEREST}

No potential conflict of interest relevant to this article was reported.

\section{REFERENCES}

1. Cosnes J, Cattan S, Blain A, Beaugerie L, Carbonnel F, Parc R, et al. Long-term evolution of disease behavior of Crohn's disease. Inflamm Bowel Dis 2002;8:244-50.

2. Leighton JA, Shen B, Baron TH, Adler DG, Davila R, Egan JV, et al. ASGE guideline: endoscopy in the diagnosis and treatment of inflammatory bowel disease. Gastrointest Endosc 2006;63:558-65.

3. Allez M, Lemann M, Bonnet J, Cattan P, Jian R, Modigliani R. Long term outcome of patients with active Crohn's disease exhibiting extensive and deep ulcerations at colonoscopy. Am J Gastroenterol 2002;97:947-53.

4. Pietropaolo V, Hassan C, Pontone S, Onorato M, Pedretti G, Zullo A. Ileal intubation with a transnasal endoscope. Eur J Gastroenterol Hepatol 2010;22:374-5.

5. Paonessa NJ, Rosen L, Stasik JJ. Using the gastroscope for incomplete colonoscopy. Dis Colon Rectum 2005;48:851-4.

6. Hunt RH. Towards safer colonoscopy. Gut 1983;24:371-5.

7. Park SH, Lee JH, Lee SS, Kim JC, Yu CS, Kim HC, et al. CT colonography for detection and characterisation of synchronous proximal colonic lesions in patients with stenosing colorectal cancer. Gut 2011 Nov 23 [Epub]. http://dx.doi.org/10.1136/gutjnl-2011301135 . 